\title{
The Information Society : What Next?
}

\author{
Penny Duquenoy \\ Chair of IFIP Working Group 9.2 (Social Accountability) \\ Senior Lecturer at Middlesex University - UK \\ P.Duquenoy@mdx.ac.uk
}

\begin{abstract}
Addressing the issues of governance, ethics and social consequences in today's Information Society is a monumental task. The authors who have contributed to this publication have risen to the challenge and produced papers that offer a variety of perspectives reflecting their different disciplines. This Chapter attempts to give an overview of the theme of the conference and the work contained within this book by drawing out the potential for influencing policy and the development and deployment of future technologies. It does this by using a stakeholder categorisation in terms of: international, governmental, organisational, educational and individual. Professionals and professional bodies have a major role in promoting awareness, and the ways in which they can do this are discussed. Finally, following the original conference programme, the steps that can be taken by Working Group 9.2 within IFIP together with the recommendations made at the end of the conference are briefly summarised.
\end{abstract}

Keywords: policy, education, social and ethical awareness, professionalism, professional bodies.

\section{Introduction}

The theme at the heart of the event leading to this publication is one which concerns the involvement of citizens in a society increasingly influenced by technology. The influence has been so great that the terms "Information Society" and "Information Age" are in common use. The issue for discussion is not so much whether citizens are involved - they clearly are - but is more in terms of how and to what extent they are involved as regards their status as citizens. That is, how far have democratic principles informed this society currently being created and that we now find ourselves in. Given that the 'Information Society' is understood as describing an environment that incorporates the characteristics of social constructs, the question of individual participation is not a trivial one - it is one of legitimacy. If democracy

Please use the followitg fornat when citing this chapter:

Duquenoy, P’.. 2007, in II IP' International lederation for Information Processing, Volume 233, The Information Society: Innovations, Legitimacy, Ethics and Democracy, eds. P. Goujon, Lavelle, S., Duquenoy, P., Kimppa, K., Laurent, V., (Boston: Springer), pp. $263-268$. 
stands for the right to participate in the governance of society then it follows that those same prerogatives should apply in an 'information' society.

In the preceding chapters we have been reminded of the degree to which information and communication technologies (ICT) have permeated social structures and have changed social practices in the government, commerce, finance, education and health sectors. Thus the arguments of these authors centre on the opportunities offered by ICT for a democratic society, but which in the creation of the new information society have been largely ignored at the most fundamental level. That is, the opportunity for the citizens to be included in the process of change as opposed to passive receivers of the combined driving forces and policies of government, commerce and the technological imperative. We are reminded of the powerful influence of external forces (for example, the economic power of the financial markets) and we could wonder whether any attempt at citizen empowerment is likely to make a difference.

The observations, research, and theoretical positions of the authors all highlight the different approaches available to influence future developments, and it appears that positive moves are underway. Although at times, for those involved in the 'social and ethical impact' movement such as IFIP TC9 and its working groups, our work seems to progress rather slowly, there is a growing awareness of the advantages of a multi-stakeholder approach and of the issues that concern us.

\section{Taking a holistic view}

The contributions in this book have addressed the questions of democracy and governance in its various manifestations: the political, economic and ethical dimensions in the context of the technological background of the information society.

By taking these different perspectives we have gained a holistic view of the influences at work, and can see more clearly how we, in turn, may take a strategic approach in influencing future developments. Although the view is decidedly European the influences of policy, economics and education can be applied in any context. The legal and ethical viewpoints, however, are culturally influenced and stem from the values held to be of importance within a given society. The challenges of the global information society are still to be overcome, and in truth may never be, although we can see that efforts are being made at an international level by, for example, the United Nations in their organisation of the World Summit on the Information Society (WSIS) (Berleur, this volume).

If we then take a stakeholder approach (as promoted by WSIS) and look at the levels of influence discussed in this book: international, governmental, organisational, educational and individual we are better placed to see where each of us - in our various areas of work - can make a contribution.

International: Clearly the international arena is vital in setting the agenda and goals for governments to pursue. In respect of ICT Jacques Berleur (in this volume) has noted the key role of technology as "powerful tools to foster socio-economic development ... and contribute to ... internationally agreed development goals" (UN Resolution, December 2002). 
Governmental: The European Union through its policies and directives sets the tone for the governments within the EU, most obviously impacting on legislation but also on research and development. The social-economic impact of technology has long been a part of the research agenda, and in recent years we have seen an increase in interest in ethical evaluations and assessments. Dissemination and communication are vital areas in this respect (Laopodis, in this volume) both within the European Commission research departments, and to the public: "The Commission sees that to exploit the economic potential of RFID, privacy and consumer concerns associated with the use of RFID tags need to be handled constructively, with the assent of all stakeholders." (Defraigne, this volume).

Organisational: Although the current trend for promoting Corporate Social Responsibility has its drawbacks (Defraigne, in this volume) and may often be interpreted as a 'tick-box' exercise, the fact that organisations are - for whatever reason - signing up to it, allows some room for influence. In practical terms - as outlined by Defraigne - CEO's are rarely given enough time to put in place long term strategies, and the financial markets drive the agenda. However, the example of the withdrawal of the Norwegian Government pension fund from Wal-Mart demonstrates that ethical choices can be made. We have also seen over the last few years an interest from the general public in 'ethical companies' (as shareholders and consumers) which has had some impact.

Educational: There are practical ways to raise awareness of social and ethical issues through formal education (Marten; Neal; in this volume) in school IT programmes, and at undergraduate level in the Computing Science curricula. The reports given during this conference are very positive and show that these age groups can be engaged in this debate. These technologies and their future counterparts are arguably more relevant to these up-and-coming citizens of the Information Society than to anyone else, and much more could be done in this area. Continuing Professional Development is another way of bringing these issues to the attention of the professional in their respective fields of expertise (see e.g. Johnson, in this volume). Last, but by no means least, is the education of the public which has until now been via the media, and has seen some success.

Individual: The influence of individuals is perhaps greater than may be apparent at first sight. Individuals are often thought of as end-users who on the whole are not equipped to take on the social and ethical challenges of ICT (due to lack of familiarity with the 'digital domain'). This view, however, merits further investigation. We have seen above that the EU is keen to get the users' 'on board' they are vital if new technologies are going to be economically successful; also mentioned above is the role played by individuals as shareholders in organisations. Finally, individuals as citizens are beginning to find their voice. The Internet more than any other communications technology allows individuals the space to express their views, and although this may not reflect any democratic process as discussed by Rodotà or Kettner (in this volume) concerns can be aired.

In all of the above areas, we can see that there is not only a potential for influencing change, but that the social and ethical context is represented - perhaps not to the extent we would like to see, but nevertheless we have a foundation for improvement. 


\section{The role of the professional and professional bodies}

In the previous section I said that by looking at the different levels of influence we could, in our own areas of work, make a contribution towards democratising new technologies and raise the profile of their social and ethical dimensions. In this context the role of the professional and professional bodies has major significance.

The conference which took place in May 2006 and this book are the result of a joint collaboration between the University of Namur, and IFIP. IFIP' is a "nongovernmental, non-profit umbrella organization for national societies working in the field of information processing" and its mission is to "encourage and assist in the development, exploitation and application of Information Technology for the benefit of all people". Professional bodies in the ICT field, and their membership, thus have through IFIP an international forum and an international voice. Through the work of the Technical Committees, Working Groups and Special Interest Groups operating within IFIP knowledge and experience can be shared between professionals and disseminated to a wider audience (as for example, this publication). IFIP has links with the United Nations (it was established in 1960 under the auspices of UNESCO) and as a result can claim a certain legitimacy in the international arena. As an organisation comprised of experts in ICT it is well placed to extend its influence beyond its membership to policy at decision makers at international level. Much more could be made of this, and indeed through the redevelopment of its Strategic Plan this is what it is aiming to do (among other things).

As far as addressing the social and ethical consequences of ICT, the Working Group 9.2 and Special Interest Group 9.2.2 brings together a community with expertise in different disciplines to work on projects and initiatives aimed at raising awareness on a general level as well as in detail ${ }^{2}$. Representatives from the national societies (relating to computer professionals) are included in discussions and events, and in this way can act as mediators - sharing best practice, and giving feedback to the national societies. In this way these groups attempt to bring influence to the professional bodies. The work of SIG 9.2.2 in particular has a direct bearing on the promotion of professionalism. Originally tasked with the investigation of Codes of Conduct of the national societies (Berleur and Brunnstein, 1996) its work has been concerned with informing the professional societies (Berleur et.al. 1999), and giving advice on how to write a code of conduct (Berleur et.al. 2004). As this list of publications shows, the key initiator of these projects has been Jacques Berleur - just one of his many contributions to this field.

What role can professional bodies take themselves to promote awareness? As well as producing Codes of Conduct for current membership, some have taken responsibility in respect of future professionals. The British Computer Society (BCS), through its accreditation system of UK university degrees, states that courses seeking "accreditation must cover the legal, social, ethical and professional issues relating to information systems engineering" (Neal, in this volume). This policy initiative has a direct influence on the graduating professionals in the UK, and courses in the UK reflect issues directly relevant to the development, design and

1 www.ifip.org

2 A summary of publications and events can be found from the IFIP web site (www.ifip.org) and following the link to TC9. 
implementation of information and communication systems. For its existing membership of practising professionals the BCS has recently established an Ethics Forum "in recognition of the role of ethics within the professional domain" to "provide a strategic link between practitioners and external parties concerned with the ethical dimension of computer technologies". 3

\section{Next steps}

In the concluding part of the conference in May the Working Group 9.2 facilitated group discussions on how the agenda for promoting the social and ethical aspects of ICT could be moved forward. As we have seen from the work described above much is being done, but there is much more to do - particularly in influencing future developments. Recommendations were made in line with the categories given above i.e. EU level, IFIP level and the professional societies. These were, in brief:

- Pursue the lobby at EU level

- Make use of the expertise in the IFIP community to bring case studies as analogies to stakeholders

- Create a dialogue within IFIP in terms of education and encourage new approaches to addressing the issues by offering a special award to graduates

- Produce short informative papers

- Initiate a dialogue on corporate social responsibility

As individuals and professionals we need to be conscious of the ICT that we use and the choices we make, and as professionals contribute to continuing professional development (our own, and our colleagues).

\section{Conclusions}

From the wealth of expertise represented in this publication we can see that we are merely at the beginning of a substantial journey. There are many issues to be addressed, and it is likely that as the pace of technological development increases there will be many more that have not yet been thought of. However, we should not despair. This publication is an indication of the growing concern regarding these issues, and the awareness of many (e.g. individuals using the Internet to communicate their concerns, and civil liberties groups). It is also an indication of a commitment to pursue a goal that brings citizens of the information society into the debate, and that aims for a better technological environment.

These goals can be achieved through the continuing work at all levels to influence the debate, the policies that guide development, and the education of professionals and citizens. Although it may seem a daunting task we are not working in isolation but as individuals within communities of professional practice. The papers presented here show how widely the communities of interest are spread, and bring the expertise necessary to influence the future - the case studies, the methodologies proposed and the sectors that have been represented have provided the material for a firm foundation of further work.

3 www.bcs.org/forums/ethics 
It is a testament to the work of Jacques Berleur that such a diverse, informed, insightful and intellectually stimulating body of knowledge has been brought together following an event in honour of his work. For those who have known him as a member of WG9.2 and as Chair of SIG 9.2.2 this is not surprising, it is no more than he deserves for his tireless input, commitment "to the cause", uniqueness, humour, warmth and last but not at all least - hospitality. On behalf of the members of WG 9.2 and myself personally: Thank you Jacques, it has been a pleasure to work with you.

\section{References}

Berleur, J. and Brunnstein, K. (Eds.) Ethics of Computing: Codes, Spaces for Discussion and Law. A Handbook prepared by the IFIP Ethics Task Group, London: Chapman \& Hall, 1996, 336 p., ISBN 0-412-72620-3.

Berleur, J., Duquenoy,P. and Whitehouse, D. (Eds.). (1999). Ethics and the Governance of the Internet, IFIP, Laxenburg, Austria. 56p.

Berleur, J., Duquenoy, P., Holvast, J., Jones, M., Kimppa, K., Sizer, R. and Whitehouse, D. (on behalf of IFIP-SIG9.2.2). Criteria and Procedures for Developing Codes of Ethics or of Conduct (To Promote Discussion Inside the IFIP National Societies), IFIP Press, Laxenburg - Austria, September 2004, ISBN 3-901882-19-7, http://www.info.fundp.ac.be/ jbl/IFIP/Criteria_and_procedures.pdf 